\title{
Optic neuritis in a child with biotinidase deficiency: case report and literature review
}

This article was published in the following Dove Press journal:

Clinical Ophthalmology

12 March 2012

Number of times this article has been viewed

\author{
Abdul-Aziz Hayati' \\ Wan-Hazabbah Wan-Hitam' \\ Min-Tet Cheong' \\ Rohaizan Yunus ${ }^{2}$ \\ Ismail Shatriah' \\ 'Department of Ophthalmology, \\ School of Medical Sciences, Universiti \\ Sains Malaysia, 16150 Kubang Kerian, \\ Kelantan, Malaysia; ${ }^{2}$ Department \\ of Radiology, School of Medical \\ Sciences, Universiti Sains Malaysia, \\ I6I50 Kubang Kerian, Kelantan, \\ Malaysia
}

\begin{abstract}
Optic atrophy has often been reported in children with biotinidase deficiency. The visual prognosis is usually poor. This report is of a 6-year-old boy with an early onset of biotinidase deficiency who presented with acute profound visual loss in both eyes. Fundoscopy revealed swollen discs in both eyes, and the imaging was consistent with bilateral optic neuritis. He was treated with systemic corticosteroid, and commenced on oral biotin. The final visual outcome was promising.
\end{abstract}

Keywords: optic neuritis, children, biotinidase deficiency

\section{Introduction}

Acute optic neuropathy is an inflammatory disorder of the optic nerve. Childhood optic neuritis is an uncommon condition which differs from adult onset optic neuritis. It is frequently associated with systemic infections such as measles, mumps, chicken pox, pertussis, infectious mononucleosis, and immunizations. Less common causes include multiple sclerosis or part of a more diffused demyelinating disorder such as acute disseminated encephalomyelitis or neuromyelitis optica.

Biotinidase deficiency is an autosomal recessive inborn error of biotin metabolism. Poor vision secondary to optic atrophy in patients with biotinidase deficiency has been described in the literature. ${ }^{1-7}$ This report is on a young boy with biotinidase deficiency who suffered an acute attack of optic neuritis in both eyes. Rapid clinical diagnosis and prompt management are essential in preventing devastating visual loss in this rare entity.

\section{Case report}

A 6-year-old Malay boy who had been diagnosed with biotinidase deficiency endured sudden reduced vision in both eyes within a period of 5 days. His teacher noted that he had difficulty with colors during an art lesson. His mother observed that he bumped into objects at home.

Based on further questioning, it was discovered that he had retro-orbital pain and a headache. There was no similar history in the past. He had no history of fever, symptoms of upper respiratory tract infection, recent vaccination, bleeding tendencies, or trauma.

He was diagnosed with biotinidase deficiency at 18 months of age when he presented with generalized impetigo, delayed developmental milestone, and recurrent episodes of seizure. His plasma biotin concentration was confirmed as low. His elder brother 
and two paternal uncles were also diagnosed with biotinidase deficiencies. Both parents had a consanguinity marriage.

He was started on a $6 \mathrm{mg}$ daily dose of oral biotin, however the compliance was poor. He was also suffering from bronchial asthma with a history of recurrent acute exacerbation, and was prescribed a metered-dose-inhaler of salbutamol. There had been no seizure attacks for the past 3 years and his anticonvulsant treatment was discontinued.

On examination, visual acuity was $1 / 160$ in both eyes. The anterior segment examination was unremarkable in both eyes except for the presence of a mild relative afferent pupillary defect in the right eye. Funduscopy revealed swollen and hyperemic optic discs in both eyes (Figure 1A and B). The retina was normal in both eyes. Color vision and red desaturation were generally reduced in both eyes. Visual field assessment was not performed as the patient was uncooperative.

The patient was well oriented and afebrile. He was intellectually normal. He had a steady gait. The other cranial nerve examinations were normal, and there was no lymphadenopathy elicited. Both lungs were clear, with no sign of exacerbation of bronchial asthma. His hair and hearing assessments were normal. Examination of the lower limbs revealed numerous scars from previous impetigo, healed eczema, and dry scaly skin.

Blood investigations showed normal white cell count. There was no evidence of leukocytosis or eosinophilia. Erythrocyte sedimentation rate was raised to $30 \mathrm{~mm}$ during the first hour. Serology screening for toxoplasmosis and herpes infection was negative. Antinuclear antibody screening and skin tuberculin tests were also negative.

The biotinidase activity in dried blood spots was less than $0.1 \mathrm{pmol} / \mathrm{min} / \mu \mathrm{L}$ (normal range: $6.3-9.3 \mathrm{pmol} / \mathrm{min} / \mu \mathrm{L}$ ). Plasma levels of 3-hydroxyisovalerate and 3-hydroxypropionate were increased. Similarly, the urinary levels of organic acids 3-hydroxyisovalerate and 3-hydroxypropionate were also raised.

Visual evoke potential was delayed bilaterally. Magnetic resonance (MR) imaging of orbit was consistent with optic neuritis. The brain imaging was normal (Figure 2A and B). Cerebrospinal fluid analysis was within normal range for cell counts, protein, sugar, and gamma globulin levels.

He was started on intravenous methylprednisolone $125 \mathrm{mg}$ 6-hourly for 3 days, followed by oral prednisolone $1 \mathrm{mg} / \mathrm{kg}$ daily for 11 days. The dosage was tapered down slowly. He was also recommenced on oral biotin $10 \mathrm{mg}$ daily. The optic nerve functions were monitored closely. He showed remarkable improvement with the above treatment.

His visual acuity improved to 6/7.5 in both eyes after 1 month. Color vision and red desaturation were subsequently improved. Both fundi showed normal and a well-defined margin of the optic discs (Figure 1C and D). The urinary organic acid profile returned to normal 1 month after oral biotin therapy. His case was followed up for 1 year and visual acuity in both eyes remained good with no sign of recurrence.

\section{Discussion}

Deficiency of biotinidase enzyme causes loss of biocytin in urine and progressive depletion of biotin which results in multiple carboxylase deficiency. It is characterized by neurological and cutaneous manifestations, and metabolic abnormalities. Classically, it is presented with hypotonia, seizures, ataxia, dermatitis, alopecia, and recurrent infections during the first year of life. ${ }^{8}$ Progressive neurological damage such as sensorineural hearing loss, optic atrophy, ataxia, and mental retardation has been described in older children. ${ }^{8-10}$

Salbert et al described 51\% ophthalmic abnormalities in 78 symptomatic children with biotinidase deficiency. ${ }^{1}$ This included $30 \%$ infections, 13\% optic neuropathies, $13 \%$ motility disturbances, $4 \%$ retinal pigment changes, and $1 \%$ pupillary findings, while the most common features were optic atrophy and keratoconjunctivitis. ${ }^{1}$

Table 1 summarizes cases of optic neuropathy in children with biotinidase deficiency published in PubMed ${ }^{11}$ from 1997 to 2011. Our search was made on keywords of "optic neuropathy," "child," and "biotinidase deficiency". We documented seven patients, and reviewed their age, gender, ocular features, funduscopy, systemic features and onset of biotinidase deficiency, treatment received, and their final visual outcome. They presented with ocular signs at ages ranging between 5 and 15 years old. Six of seven patients $(85.7 \%)$ presented with optic atrophy in both eyes, while the remaining one patient (14.3\%) displayed normal looking optic discs bilaterally. ${ }^{2-5,9-10}$ Unfortunately, the final visual outcome was poor in $71.4 \%$ (five patients). ${ }^{2-5}$

In contrast, Puertas et al reported a 12-year-old boy with biotinidase deficiency and presented symptoms of acute retrobulbar neuritis in both eyes. ${ }^{9}$ Similarly, our patient also exhibited acute papillitis in both eyes. These two patients were identified during the acute attack, and they were successfully treated with a combination of intravenous corticosteroid and oral biotin. Their final visual acuity was satisfactory.

Our patient had poor compliance to biotin therapy. His biotinidase activity was confirmed low (less than $0.1 \mathrm{pmol} / \mathrm{min} / \mu \mathrm{L}$ ), and this supports the diagnosis of biotinidase deficiency. Raised urinary levels of organic acids 3-hydroxyisovalerate and 3-hydroxypropionate suggest multiple carboxylase deficiencies in our patient. 

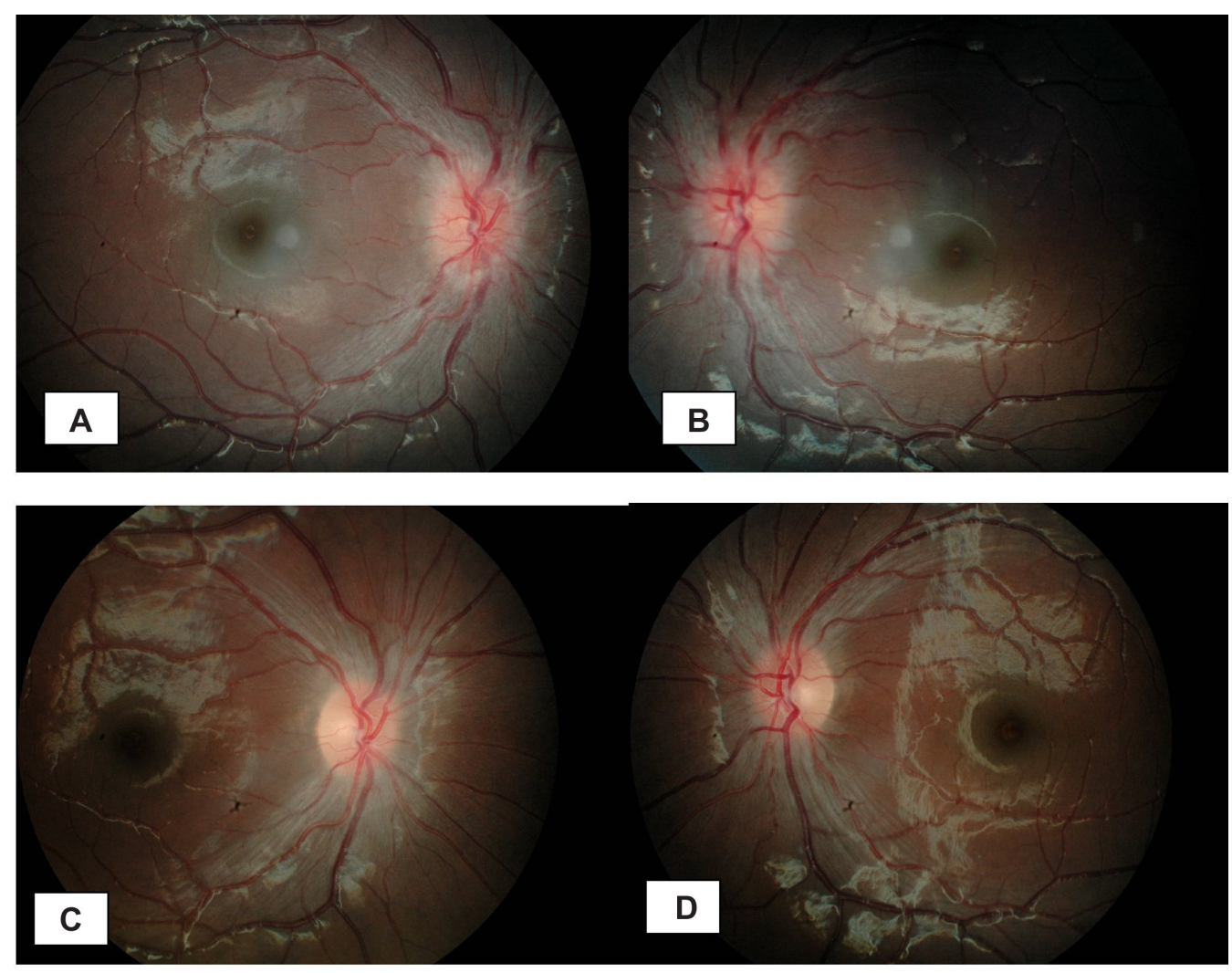

Figure I (A and B) fundus photographs show bilateral swollen disc on presentation. ( $C$ and $\mathbf{D})$ resolved bilateral disc swelling at one month after treatment.
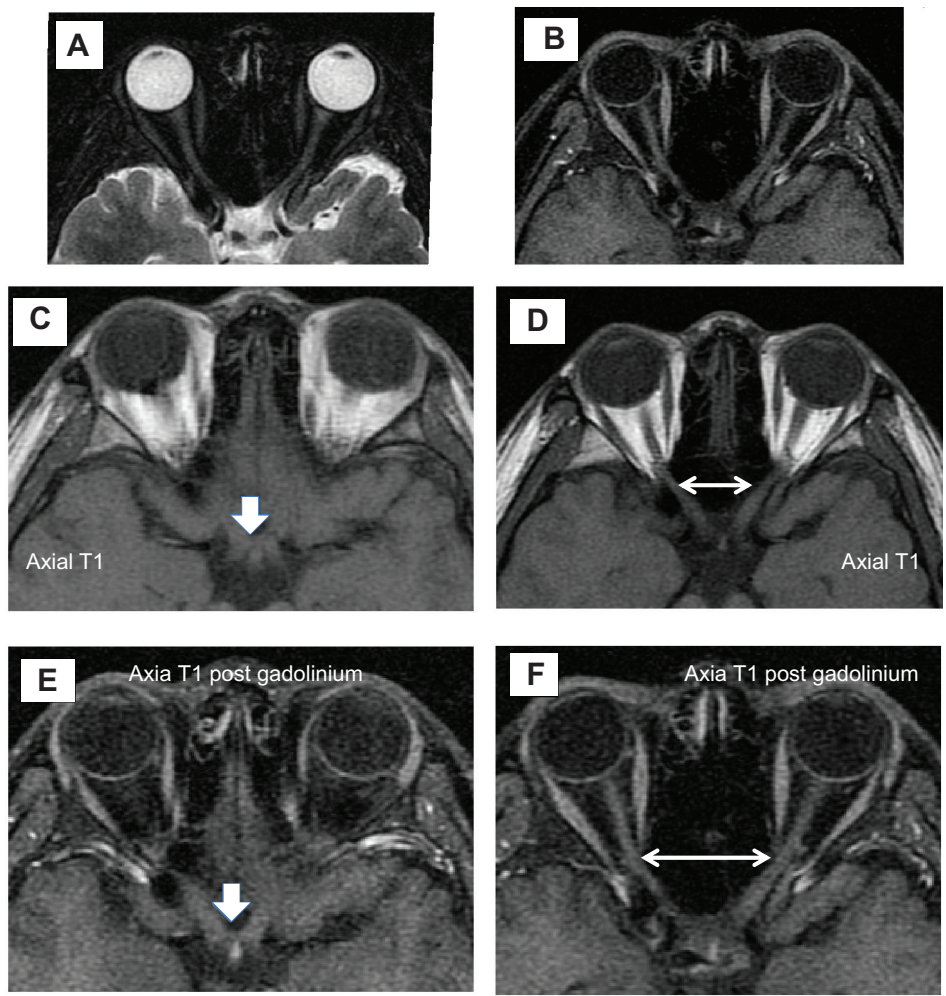

Figure 2 (A and B) MRI of the optic nerve shows expansion with slight increase signal intensity on T2-weighted image involving both optic nerves (left) and enhancement in TI-weighted image post IV contrast. (C-F) MRI of the optic nerve (white arrow) and both optic nerves (white double arrowheads) shows expansion and enhancement on TI-weighted image and post gadolinium images. Abbreviation: MRI, magnetic resonance image. 


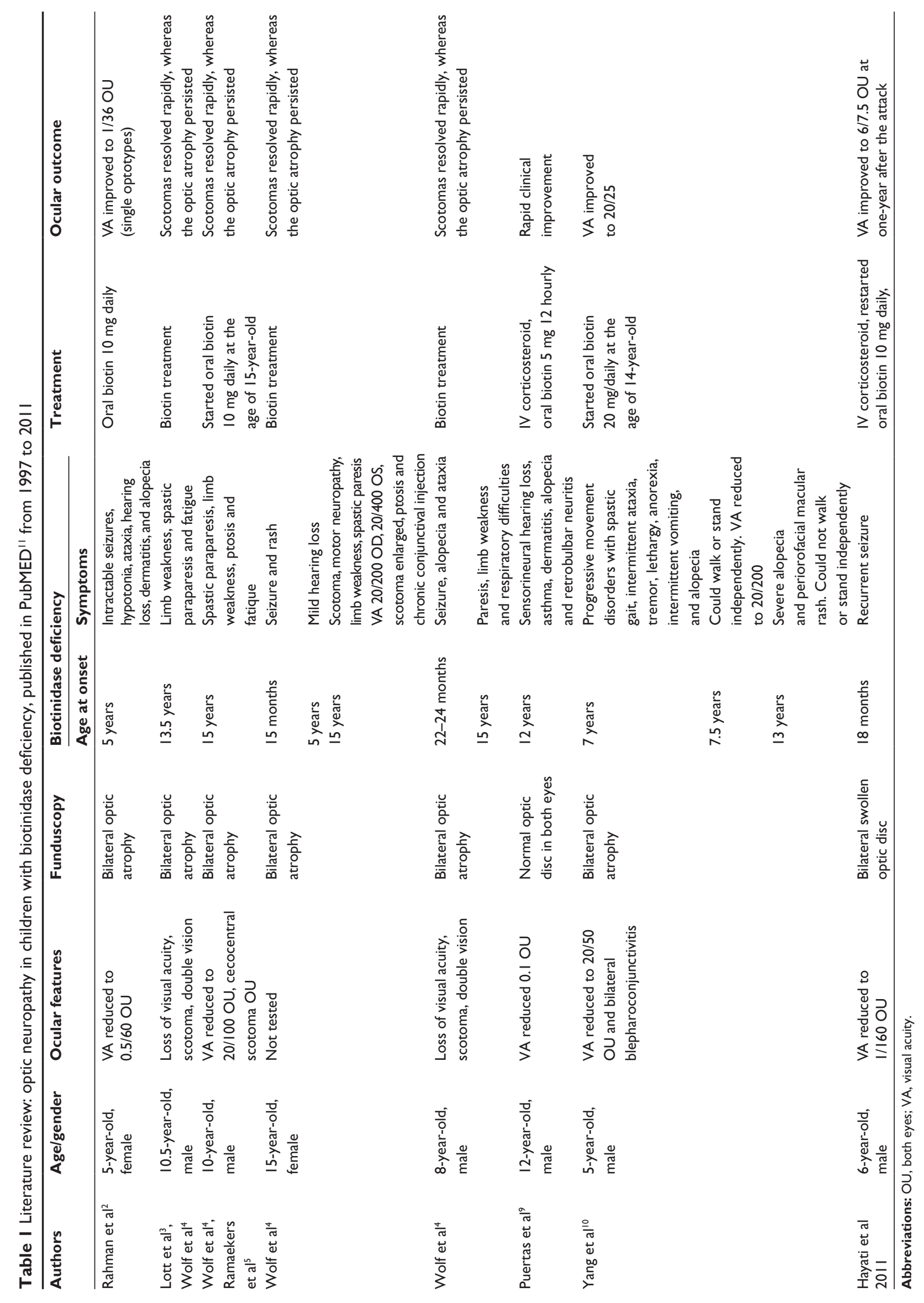


A

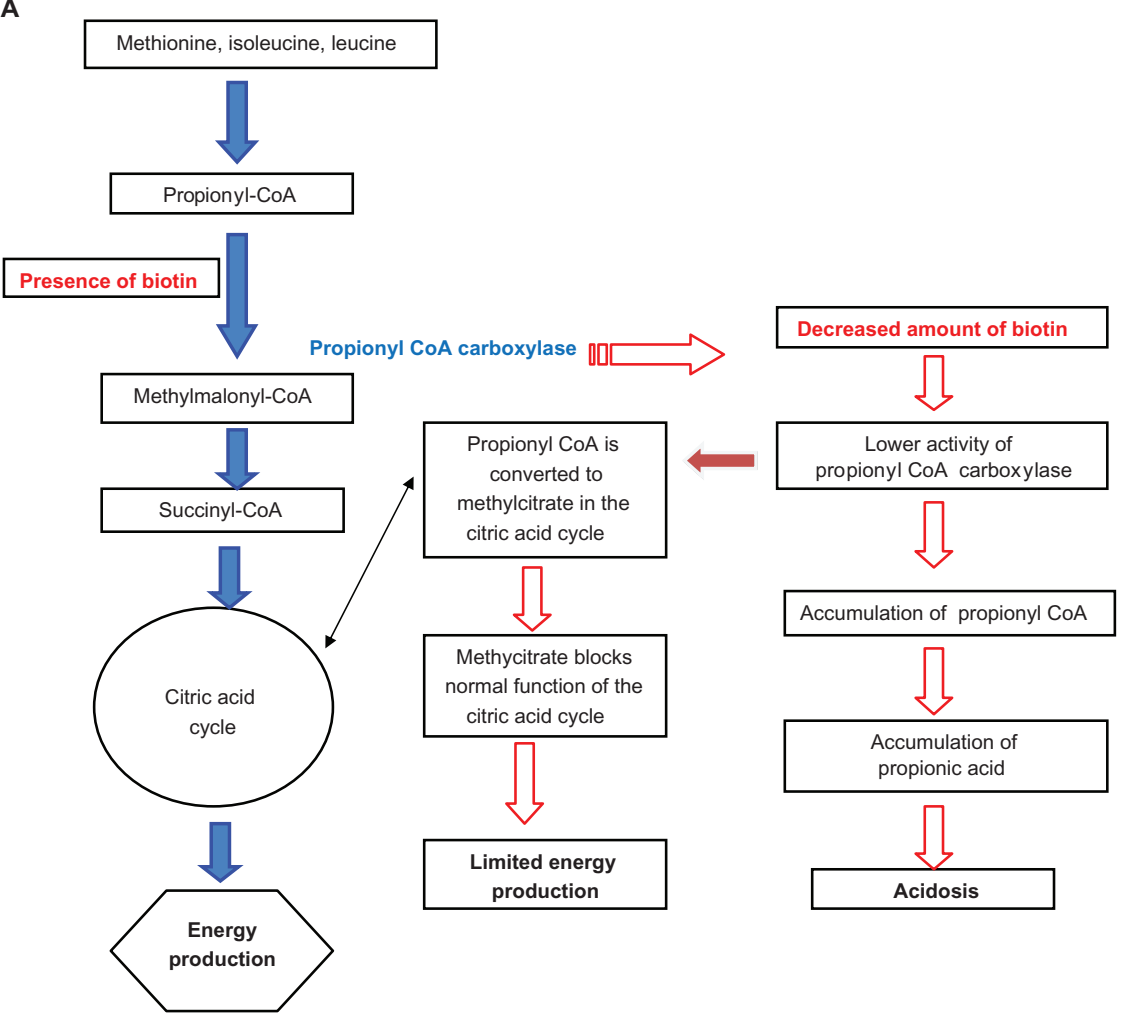

Legends:

\section{B}

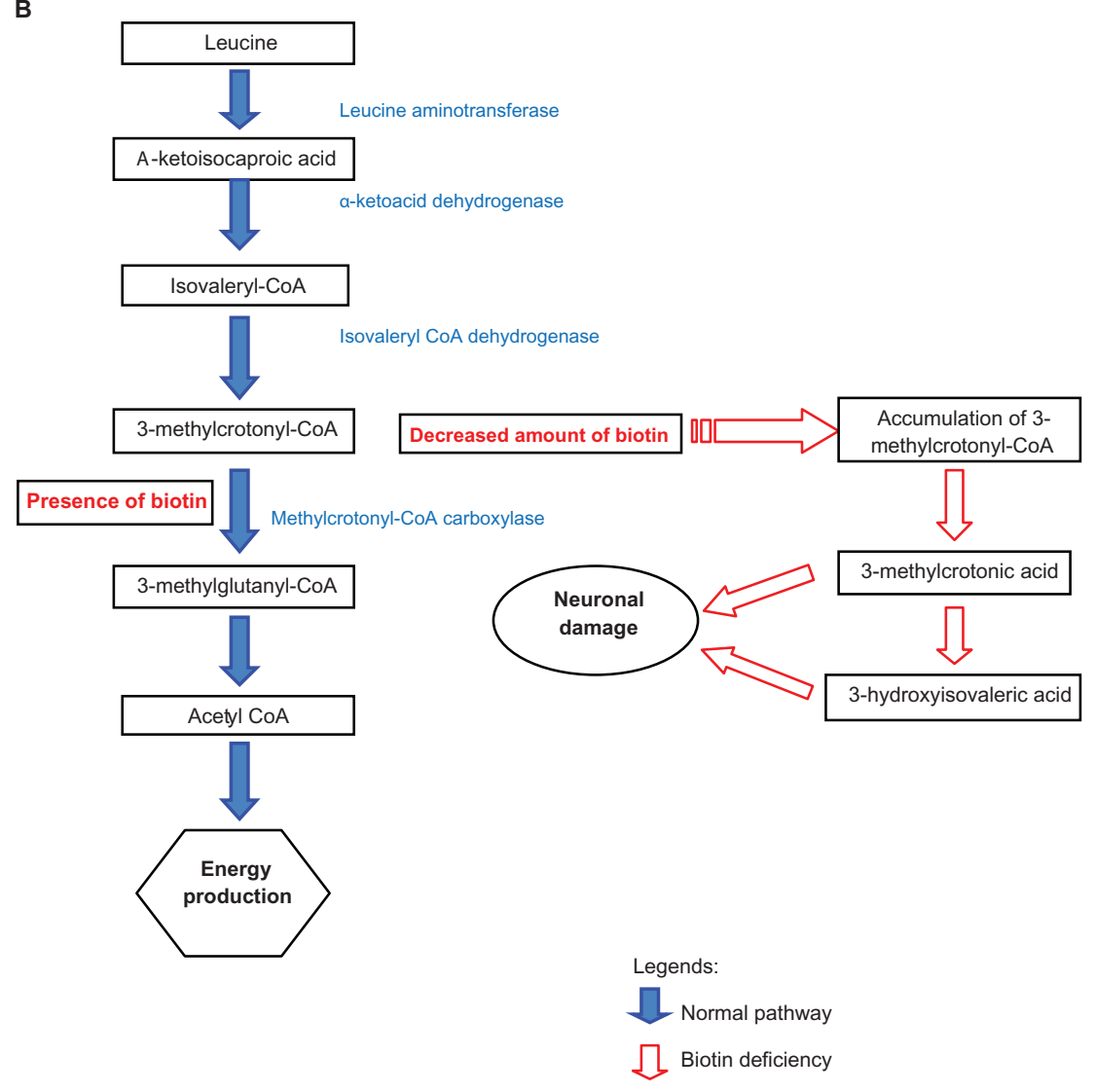

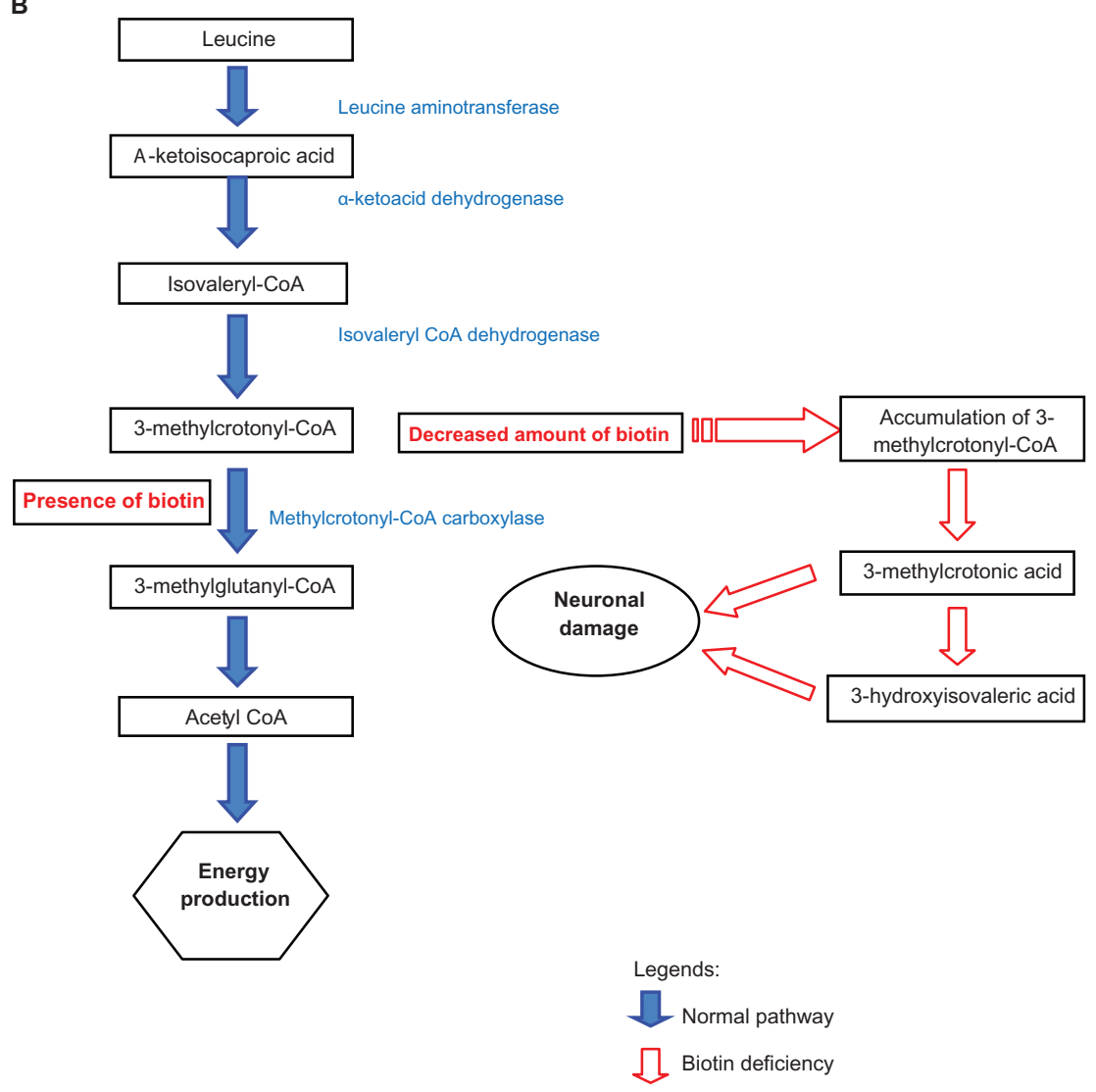

Isovaleryl CoA dehydrogenase
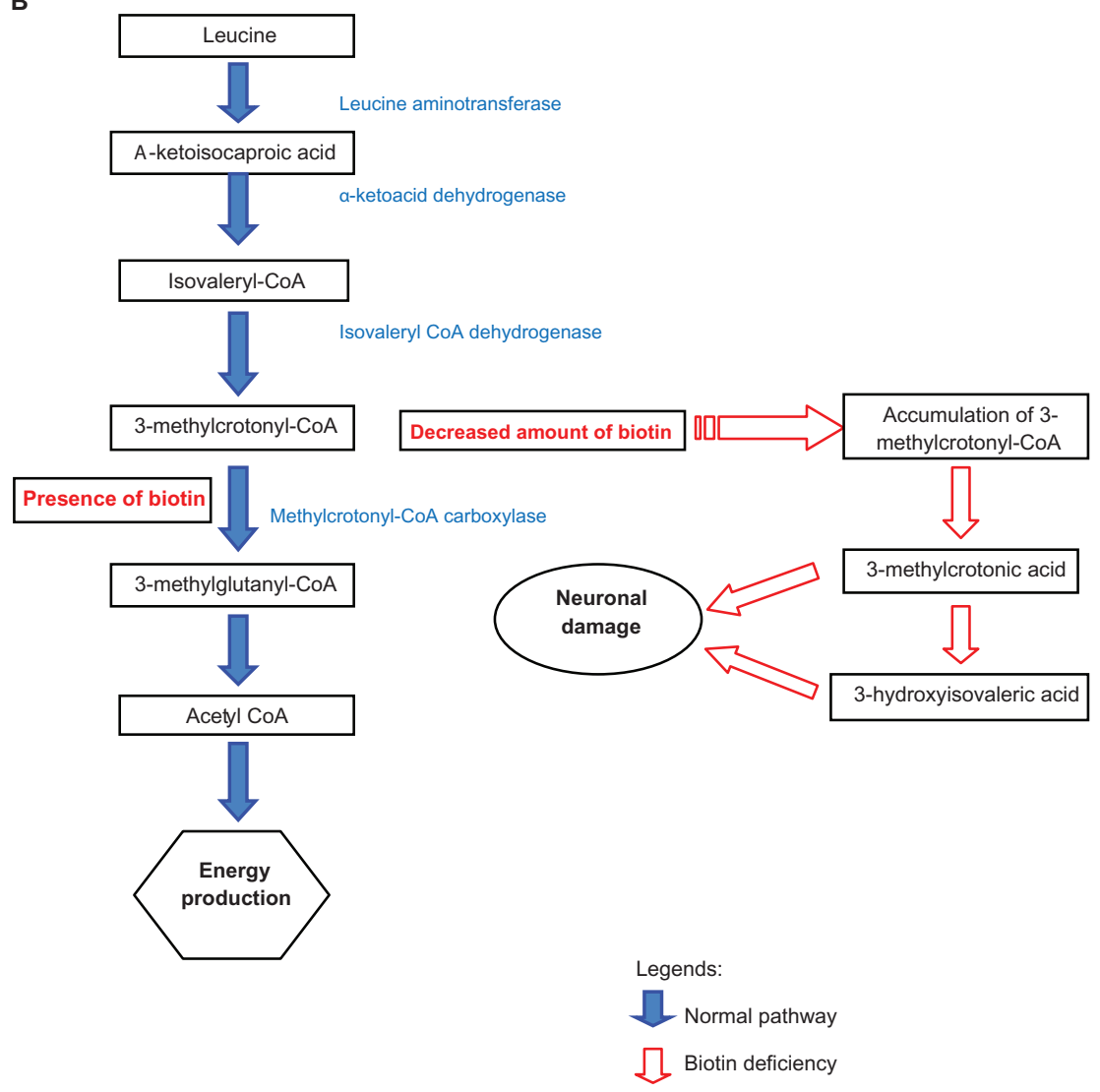
thylcrotonyl-CoA

Normal pathway

\Biotin deficiency

Figure 3 (A) Possible mechanism explains retinal ganglion cell apoptosis and acidosis in biotinidase deficiency. (B) Possible mechanism describes neuronal damage. 
A

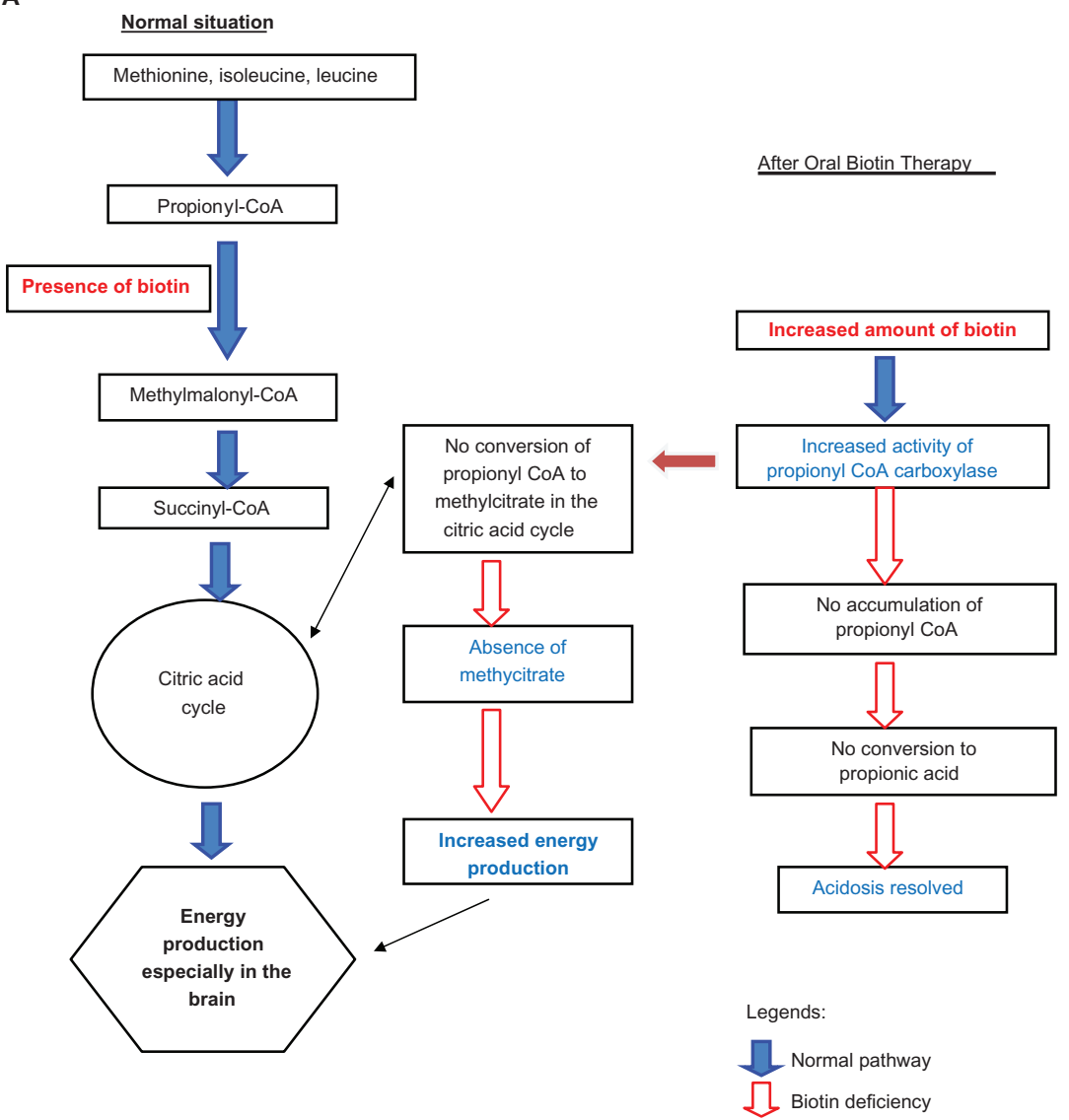

B

Normal Situation

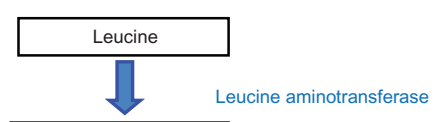

A-ketoisocaproic acid
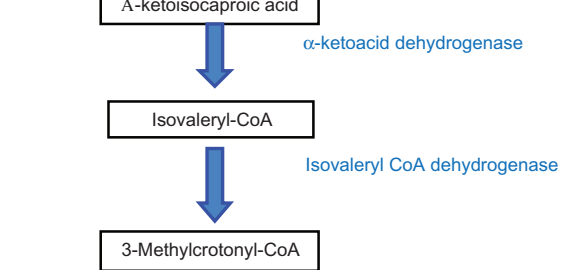

After oral biotin therapy
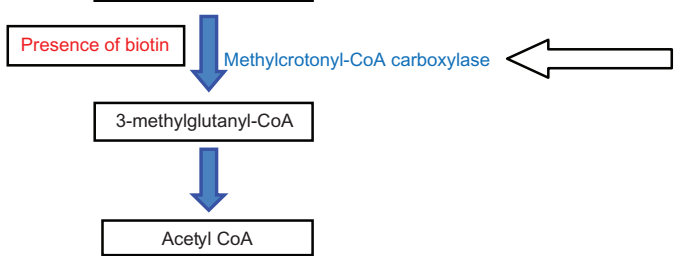

Increased amount of biotin
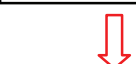

Increased activity methylcrotonyl-CoA carboxylase
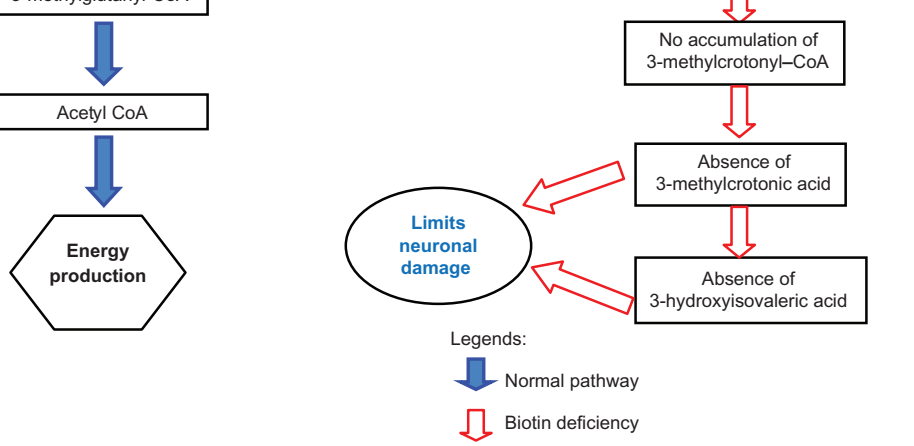

Figure 4 (A) Possible mechanism improvement of energy production to retinal ganglion cell and resolved acidosis after biotin therapy in biotinidase deficiency. (B) Possible mechanism limits neuronal damage. 
There are possible explanations regarding the occurrence of optic neuritis in children with biotinidase deficiency (Figure 3A and B). ${ }^{12,13}$ Decreased amount of biotin causes reduction of methylcrotonyl-CoA carboxylase activity. This leads to the accumulation of 3-methylcrotonyl-CoA, and subsequently the formation of 3-methylcrotonic acid. This will be modified later to 3-hydroxyisovaleric acid. Accumulation and storage of these two acids in the retinal ganglion cells directly affects the intracellular metabolism and leads to retinal ganglion cells apoptosis. ${ }^{12,13}$

Due to high energy demand and the long course of their axons, retinal ganglion cells are very susceptible to intracellular metabolic defect. In biotinidase deficiency, the decreased amount of biotin causes a lower activity of propionyl-CoA carboxylase. This leads to the accumulation of propionyl-CoA which can be converted later into propionic acid resulting in acidosis. ${ }^{12,13}$

In addition to that, propionyl-CoA can be processed into methylcitrate by an enzyme in the citric acid cycle. Methylcitrate blocks the normal function of citric acid. This causes limited energy production in the retinal ganglion cells and subsequently, results in cell apoptosis. The above factors may lead to optic neuropathy and consequently result in irreversible optic atrophy. ${ }^{12,13}$

Corticosteroid is the standard modality for treatment of optic neuritis. It acts to decrease inflammation by suppressing migration of polymorphonuclear leukocytes and reversing increased capillary permeability. The Optic Neuritis Treatment Trial ${ }^{14}$ describes the recommended treatment for adult onset optic neuritis. ${ }^{15}$ Our patient tolerated the corticosteroid therapy well.

Children with profound biotinidase deficiency have less than $10 \%$ of mean serum biotinidase enzyme activity, while children with partial biotinidase deficiency have 10\%-30\% of mean serum biotinidase enzyme activity. Both profound and partial biotinidase deficiency are usually identified by newborn screening. Unfortunately, this test is not performed routinely in our country.

Optic neuritis is uncommon in children with biotinidase deficiency. It is important for ophthalmologists and pediatricians to be aware of this diagnosis when a child with

Clinical Ophthalmology

\section{Publish your work in this journal}

Clinical Ophthalmology is an international, peer-reviewed journal covering all subspecialties within ophthalmology. Key topics include: Optometry; Visual science; Pharmacology and drug therapy in eye diseases; Basic Sciences; Primary and Secondary eye care; Patient Safety and Quality of Care Improvements. This journal is indexed on biotinidase deficiency presents symptoms of acute visual loss. Prompt diagnosis and early treatment is mandatory to avoid irreversible visual loss in these children. The combination of systemic corticosteroid and biotin treatment seemed an effective treatment with our patient.

\section{Disclosure}

The authors report no conflict of interest in this work.

\section{References}

1. Salbert BA, Astruc J, Wolf B. Ophthalmologic findings in biotinidase deficiency. Ophthalmologica. 1993;206(4):177-181.

2. Rahman S, Standing S, Dalton RN, Pike MG. Late presentation of biotinidase deficiency with acute visual loss and gait disturbance. Dev Med Child Neurol. 1997;39(12):830-831.

3. Lott IT, Lottenberg S, Nyhan WL, Buchsbaum MJ. Cerebral metabolic change after treatment in biotinidase deficiency. $J$ Inherit Metab Dis. 1993;16(2):399-407.

4. Wolf B, Pomponio RJ, Norrgard KJ, et al. Delayed-onset profound biotinidase deficiency. J Pediatr. 1998;132(2):362-365.

5. Ramaekers VT, Suormala TM, Brab M, Duran R, Heimann G, Baumgartner ER. A biotinidase Km variant causing late onset bilateral optic neuropathy. Arch Dis Child. 1992;67(1):115-119.

6. Campana G, Valentini G, Legnaioli MI, Giovannucci-Uzielli ML, Pavari E. Ocular aspects in biotinidase deficiency. Clinical and genetic original studies. Ophthalmic Paediatr Genet. 1987;8(2):125-129.

7. Coşkun T, Tokatli A, Ozalp I. Inborn errors of biotin metabolism. Clinical and laboratory features of eight cases. Turk J Pediatr. 1994;36(4):267-278.

8. Wolf B, Heard GS, Weissbecker KA, McVoy JR, Grier RE, Leshner RT. Biotinidase deficiency: initial clinical features and rapid diagnosis. Ann Neurol. 1985;18(5):614-617.

9. Puertas Bordallo D, Martín Reyes C, Ruiz-Falcó Rojas ML, Duat Rodríguez A, Valls Ferrán MI. Optic neuropathy in biotinidase deficiency. Arch Soc Esp Oftalmol. 2004;79(8):393-396. Spanish.

10. Yang Y, Li C, Qi Z, et al. Spinal cord demyelination associated with biotinidase deficiency in 3 Chinese patients. J Child Neurol. 2007;22(2):156-160.

11. PubMed.gov. National Center for Biotechnology Information, US National Library of Medicine, National Institutes of Health.

12. Huizing M, Brooks BP, Anikster Y. Optic atrophies in metabolic disorders. Mol Genet Metab. 2005;86(1-2):51-60.

13. Tischler ME. Biotin (Biotinidase) deficiency. University of Arizona. Available from: htttp:/www.wohproject.org/pdfs/biotin-deficiency.pdf.

14. National Eye Institute (NEI). Optic Neuritis Treatment Trial. In: ClinicalTrials.gov [website on the Internet]. Bethesda, MD: US National Library of Medicine; 1999 [updated June 2, 2006]. Available from: http:/clinicaltrials.gov/ct2/show/NCT00000146. NLM identifier: NCT00000146. Accessed March 1, 2012.

15. Optic Neuritis Study Group. The clinical profile of optic neuritis Experience of the Optic Neuritis Treatment Trial. Arch Ophthalmol. 1991;109(12):1673-1678.

PubMed Central and CAS, and is the official journal of The Society of Clinical Ophthalmology (SCO). The manuscript management system is completely online and includes a very quick and fair peer-review system, which is all easy to use. Visit http://www.dovepress.com/ testimonials.php to read real quotes from published authors. 